\title{
Pediatric liver transplantation with hyperreduced left lateral segment graft
}

\author{
Jung-Man Namgoong ${ }^{1}$, Shin Hwang ${ }^{1}$, Gi-Won Song ${ }^{1}$, Dae-Yeon Kim ${ }^{1}$, \\ Tae-Yong $\mathrm{Ha}^{1}$, Dong-Hwan Jung ${ }^{1}$, Gil-Chun Park ${ }^{1}$, Chul-Soo Ahn ${ }^{1}$, Kyung Mo Kim², \\ Seak Hee $\mathrm{Oh}^{2}$, Hyunhee Kwon ${ }^{1}$, and Yong Jae Kwon ${ }^{1}$ \\ Departments of ${ }^{1}$ Surgery and ${ }^{2}$ Pediatrics, Asan Medical Center, \\ University of Ulsan College of Medicine, Seoul, Korea
}

\begin{abstract}
Backgrounds/Aims: To prevent large-for-size graft-related complications in small infant patients, the size of a left lateral segment (LLS) graft can be reduced to be a hyperreduced LLS (HRLLS) graft. Methods: This study was intended to describe the detailed techniques for harvesting and implanting HRLLS grafts developed in a high-volume liver transplantation (LT) center. Results: The mean recipient age was $4.0 \pm 1.7$ months (range: $3-6$ ) and body weight was $5.3 \pm 1.4$ $\mathrm{kg}$ (range: 4.1-6.9). Primary diagnoses of the recipients were progressive familial intrahepatic cholestasis in 2 and biliary atresia in 1. The types of LT were living donor LT in 1 and split deceased donor LT in 2. Non-anatomical size reduction was performed to the transected LLS grafts. The mean weight of the HRLLS grafts was 191.7 \pm 62.1 $\mathrm{g}$ (range: $120-230$ ) and graft-recipient weight ratio was $3.75 \pm 1.57 \%$ (range: $2.45-5.49$ ). Widening venoplasty was applied to the graft left hepatic vein outflow orifice. Vein homograft interposition was used in a case with portal vein hypoplasia. Types of the abdomen wound closure were one case of primary repair, one of two-staged closure with a mesh, and one of three-staged repair with a silo and a mesh. All three patients recovered uneventfully from the LT operation and are doing well to date for more than 6 years after transplantation. Conclusions: Making a HRLLS graft through non-anatomical resection during living donor LT and split deceased donor LT can be a useful option for treating small infant patients. (Ann Hepatobiliary Pancreat Surg 2020;24:503-512)
\end{abstract}

Key Words: Infant; Large-for-size graft; Pediatric transplantation; Graft-recipient weight ratio; Left lateral segment

\section{INTRODUCTION}

In liver transplantation (LT) for small infant patients, graft size matching to the recipient's abdomen is critically important because implantation of a large-for-size graft hinders primary closure of the abdomen and can induce various vascular complications. ${ }^{1,2}$ To make a left lateral segment (LLS) graft as small as possible, a LLS can be reduced to be a monosegment or hyperreduced LLS (HRLLS) graft. ${ }^{1-4}$ Anatomical resection of the segment II or III makes a segment III or II monosegment graft, but it is technically demanding and thorough evaluation of the intrahepatic vascular and biliary anatomy is the prerequisite. $^{5-8}$ In contrast, HRLLS grafts are produced by nonanatomical resection of the peripheral liver parenchyma and its feasibility is higher than that of monosegment grafts.

Living donor liver transplantation (LDLT) has been established as the common type of LT, and the number of donor candidates enabling split LT is also increasing in Korea, but the annual number of pediatric LT cases has been stationary for the last 10 years. ${ }^{9}$ The demand for LT in small infants has been persistently present, but the number of LT using monosegment or HRLLS grafts is very limited in Korea to the best of our knowledge. Therefore, this study was intended to describe the detailed techniques for harvesting and implanting HRLLS grafts developed in a high-volume LT center carrying out LDLT and deceased donor LT.

Received: June 23, 2020; Revised: June 25, 2020; Accepted: June 29, 2020

Corresponding author: Shin Hwang

Department of Surgery, Asan Medical Center, University of Ulsan College of Medicine, 88 Olympic-ro 43-gil, Songpa-gu, Seoul 05505, Korea Tel: +82-2-3010-3930, Fax: +82-2-3010-6701, E-mail: shwang@amc.seoul.kr

Copyright (C) 2020 by The Korean Association of Hepato-Biliary-Pancreatic Surgery

This is an Open Access article distributed under the terms of the Creative Commons Attribution Non-Commercial License (http://creativecommons.org/ censes/by-nc/4.0) which permits unrestricted non-commercial use, distribution, and reproduction in any medium, provided the original work is properly cited Annals of Hepato-Biliary-Pancreatic Surgery • pISSN: 2508-5778 - elSSN: 2508-5859 


\section{MATERIALS AND METHODS}

\section{Patients}

This study was a retrospective analysis of pediatric LT using a HRLLS graft. We searched the institutional database of LT from January 2013 to December 2014, and found three cases of HRLLS graft implantation that could provide intraoperatively taken photographs showing the detailed surgical procedures. The purpose of this study was to present the detailed techniques for harvesting and implanting HRLLS grafts. The study protocol was approved by the institutional review board of the Asan Medical Center, which waived the requirement for informed consent because of the retrospective nature of this study (IRB No. 2020-0836).

\section{Selection of donor for harvest of a HRLLS graft}

The shape of the donor LLS is important for deciding whether to perform non-anatomical size reduction. If the LLS appears to be like a flat fish, it is easy and effective to perform non-anatomical resection. In contrast, it appears similar to a puffy fish, it is not indicated for nonanatomical resection because we cannot effectively reduce the graft thickness (Fig. 1).

The target of graft size reduction is to make the estimated graft-recipient weight ratio (GRWR) less than $4 \%$. Considering that the size reduction rate following nonanatomical resection is usually less than $50 \%$, the donors with LLS volume comparable to $4-8 \%$ of GRWR on computed tomography (CT) volumetry are theoretically indicated for size reduction. The graft thickness-to-anteroposterior diameter in the recipient's abdominal cavity ratio should be taken into account. ${ }^{10}$ If this ratio of thickness is less than 1.0, the donors are also indicated for size reduction. If the GRWR is less than $4 \%$ and thickness ratio is less than 1.0, such LLS grafts may not require size
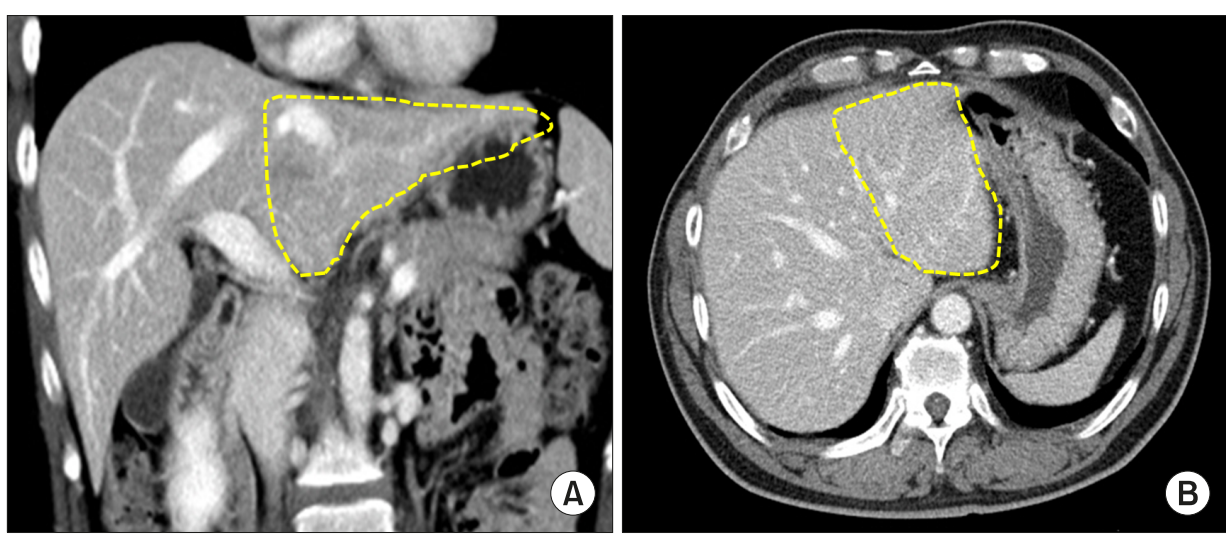

Fig. 1. Computed tomography scans showing the left lateral segment appearing to be a flat fish (A) and puffy fish (B).
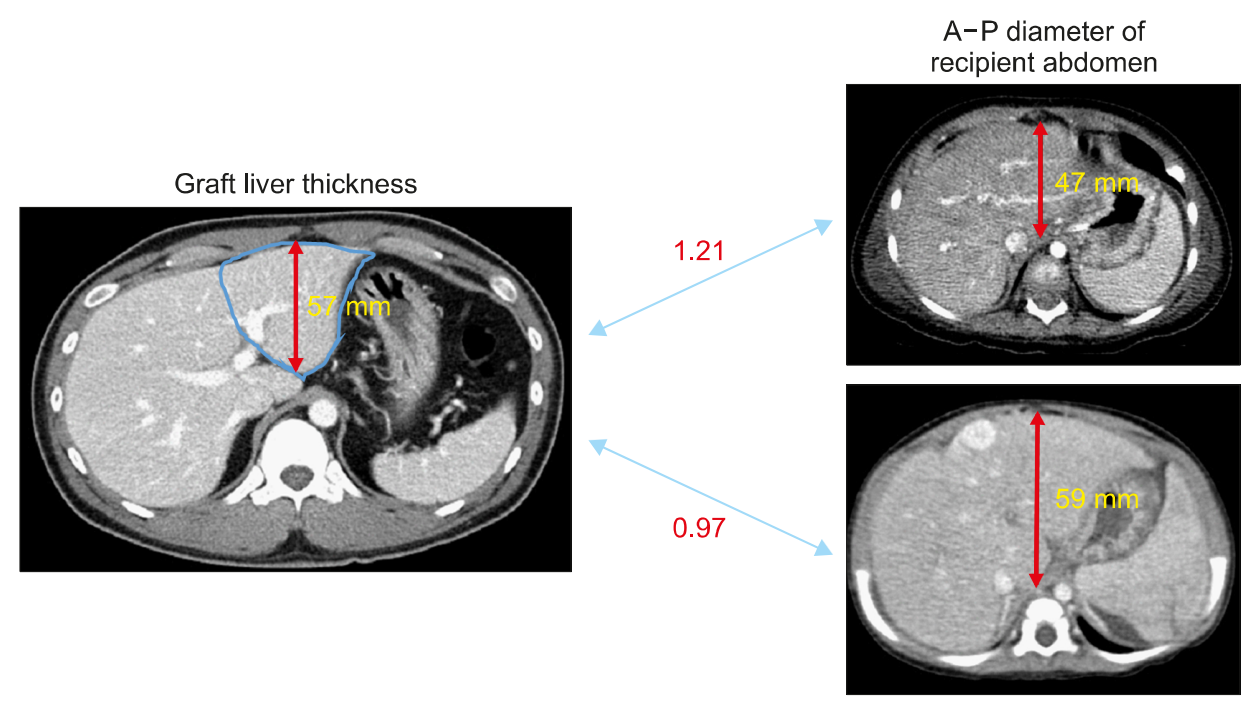

Fig. 2. Computed tomography scans showing the graft thickness-to-anteroposterior diameter in the recipient's abdominal cavity ratio. 
reduction (Fig. 2).

\section{Surgical techniques for harvesting and implanting a HRLLS graft}

The surface marking is made along the falciform ligament to split a usual LLS graft, and then additional markings are made transversely at the ventral part of the segment III and vertically at the lateral part of the segment II. First, the liver is transected to make a LLS graft. Thereafter, the parenchymal transection continues along the additional marking lines. The transection plane should be perpendicular to the intrahepatic glissonian branches in order to prevent unnecessary ischemia (Fig. 3). In LDLT, the HRLLS is recovered along the pace of recipient operation. In split LT, the HRLLS graft can be recovered in advance before the harvesting of other organs as in LDLT. This method is usually adopted if the pediatric and adult recipients are cared for in different hospitals. If the two recipients of the split liver grafts are cared for in the same hospital, whole liver harvesting after in situ splitting is preferred, because complete separation of two split liver grafts at the back table is more convenient and safe.
The left hepatic vein orifice of the HRLLS graft is often small, thus patch venoplasty is often used to enlarge the orifice. The three hepatic vein orifices at the recipient's inferior vena cava (IVC) was opened to make a large orifice, which should be much larger than the diameter of the recipient's IVC. If the recipient's native portal vein appears normal, a branch patch can be used for portal vein reconstruction. If the portal vein appears hypoplastic, we preferentially use interposition of an external iliac vein homograft. ${ }^{11}$ Since the diameter of the left hepatic artery in a HRLLS graft is often very small, we always perform arterial reconstruction under surgical microscopy. The native bile duct of the infants is very small, so hepaticojejunostomy should be used.

\section{RESULTS}

\section{Patient profiles and clinical outcomes}

The mean recipient age was $4.0 \pm 1.7$ months (range: 3-6) and body weight was $5.3 \pm 1.4 \mathrm{~kg}$ (range: 4.1-6.9). Primary diagnoses of the recipients were progressive familial intrahepatic cholestasis (PFIC) in 2 and biliary atresia
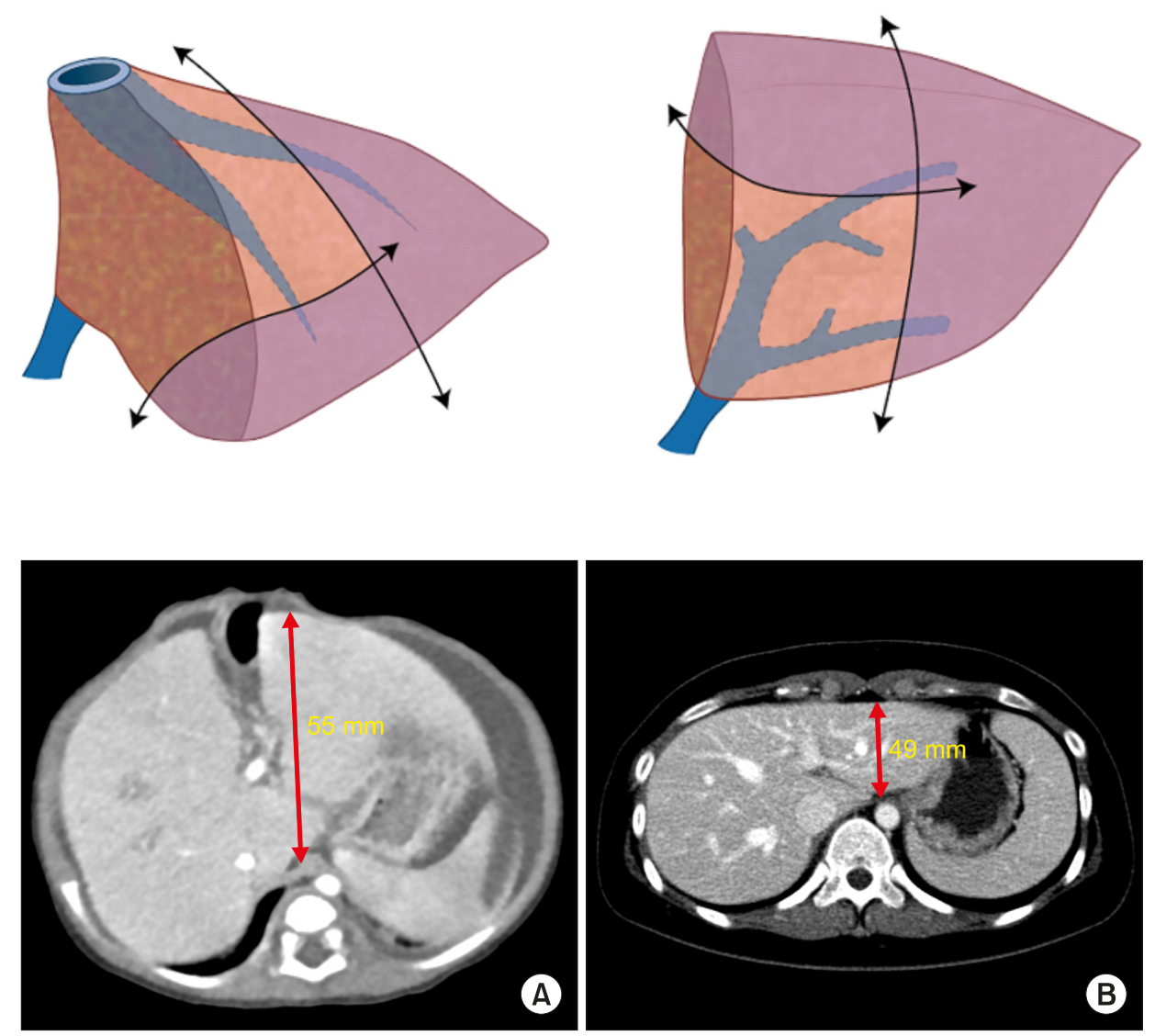

Fig. 4. Computed tomography scans showing the graft thickness (A)-to-anteroposterior diameter in the recipient's abdominal cavity (B) ratio in Case No. 1. The graft thickness ratio was 0.89 . 
in 1. The types of LT were LDLT in 1 and split deceased donor LT in 2. The mean weight of the HRLLS grafts was $191.7 \pm 62.1 \mathrm{~g}$ (range: 120-230) and graft-recipient weight ratio (GRWR) was $3.75 \pm 1.57 \%$ (range: $2.45-5.49$ ). Types of the abdominal wound closure were one case of primary repair, one of two-staged closure with a mesh, and one of three-staged repair with a silo and a mesh. All three patients recovered uneventfully from the LT operation and are doing well to date for more than 6 years after transplantation.

\section{Detailed case presentation}

Case No. 1: The patient was a 3-month-old $4.9 \mathrm{~kg}$ weighing female infant with suspected PFIC type 2. She was born at 36 weeks through urgent cesarean section because of oligohydramnios. Jaundice developed soon after birth and progressed gradually with hepatomegaly (Fig. 4A). The general condition of this patient deteriorated rapidly, so LDLT was planned. The living donor was her mother's sister, who was 29 years old. The whole LLS volume was measured to be $250 \mathrm{ml}$. The graft thickness ratio was 0.89 (Fig. 4B).

Recipient hepatectomy was performed according to the standard procedure of pediatric LDLT, and the size of the native liver was measured (Fig. 5). Donor surgery was performed through an upper midline incision. The left hepatic artery and portal vein were isolated and hepatic parenchyma was transected according to the standard pro-
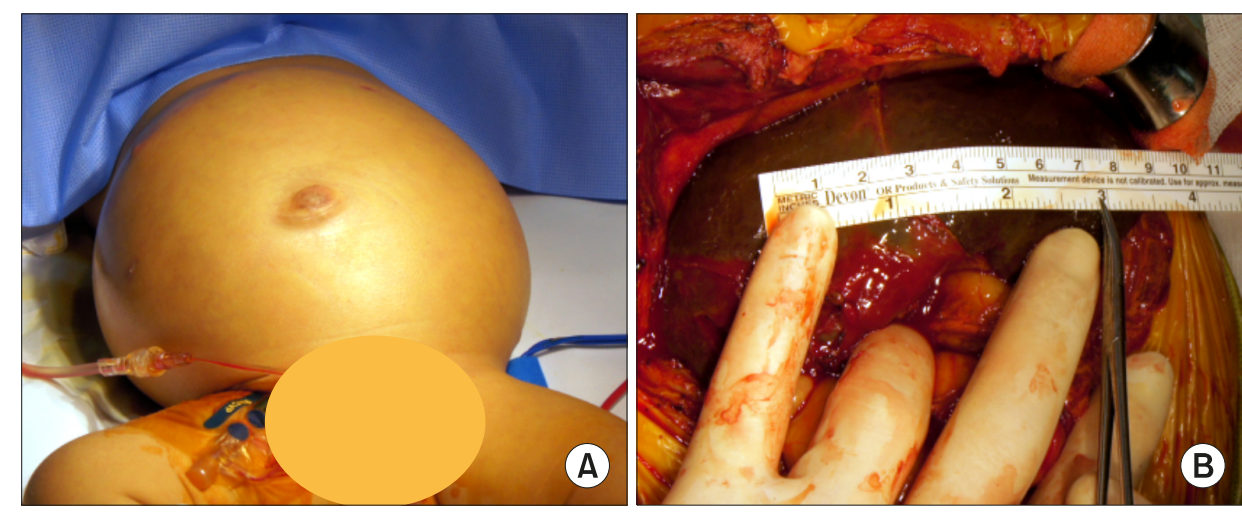

Fig. 5. Intraoperative photographs showing the size of abdomen (A) and native liver (B) in Case No. 1.
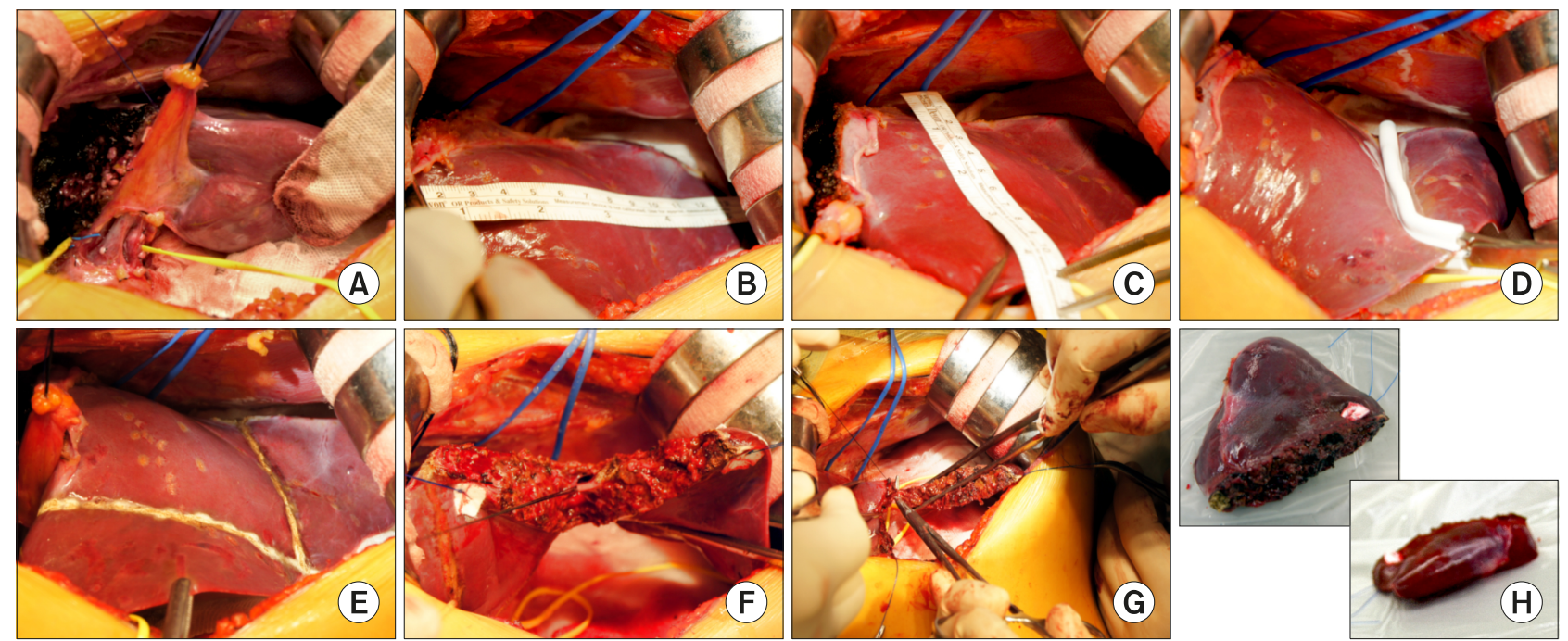

(F)
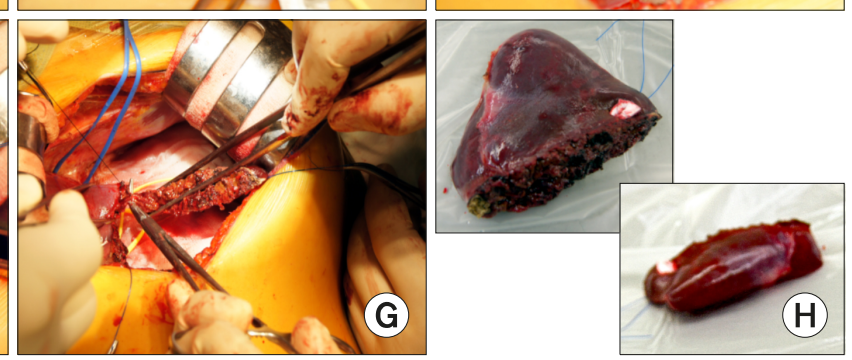

Fig. 6. Intraoperative photographs showing the surgical procedures for making a hyperreduced left lateral segment graft in Case No. 1. (A) The left hepatic artery and portal vein were isolated and hepatic parenchyma was transected. (B and C) The size of the left lateral segment graft was measured with a paper ruler. (D) Test parenchymal clamping was attempted. (E) The lines for size reduction were drawn on the liver surface. ( $F$ and $G$ ) The peripheral parts of the segment II and III were resected.

(H) Some liver parenchyma was resected from the graft. 
cedure of LLS harvest. Thereafter, the size of the LLS graft was measured with a paper ruler. Considering the size of the recipient's native liver, the lines for size reduction were drawn on the liver surface. The peripheral parts of the segment II and III were resected with a Cavitron ultrasonic aspirator (CUSA). The resected liver fragments from the segment II and III weighed $70 \mathrm{~g}$ and $25 \mathrm{~g}$, respectively (Fig. 6).

The HRLLS graft was harvested and its weight was 120 g, making a GRWR of $2.45 \%$. Graft implantation was performed according to the standard procedure of LDLT using a LLS graft. Reconstruction was done in the order of hepatic vein, portal vein, hepatic artery and Roux-en-Y hepaticojejunostomy. The posttransplant recovery was uneventful except for production of ascites for a prolonged period (Fig. 7). This patient was discharged at 47 days after transplantation. Currently, she has been doing well for more than 7 years after transplantation.

Case No. 2: The patient was a 3-month-old $4.1 \mathrm{~kg}$ weighing female infant clinically diagnosed with PFIC. She was born in full-term spontaneous delivery. Soon af-
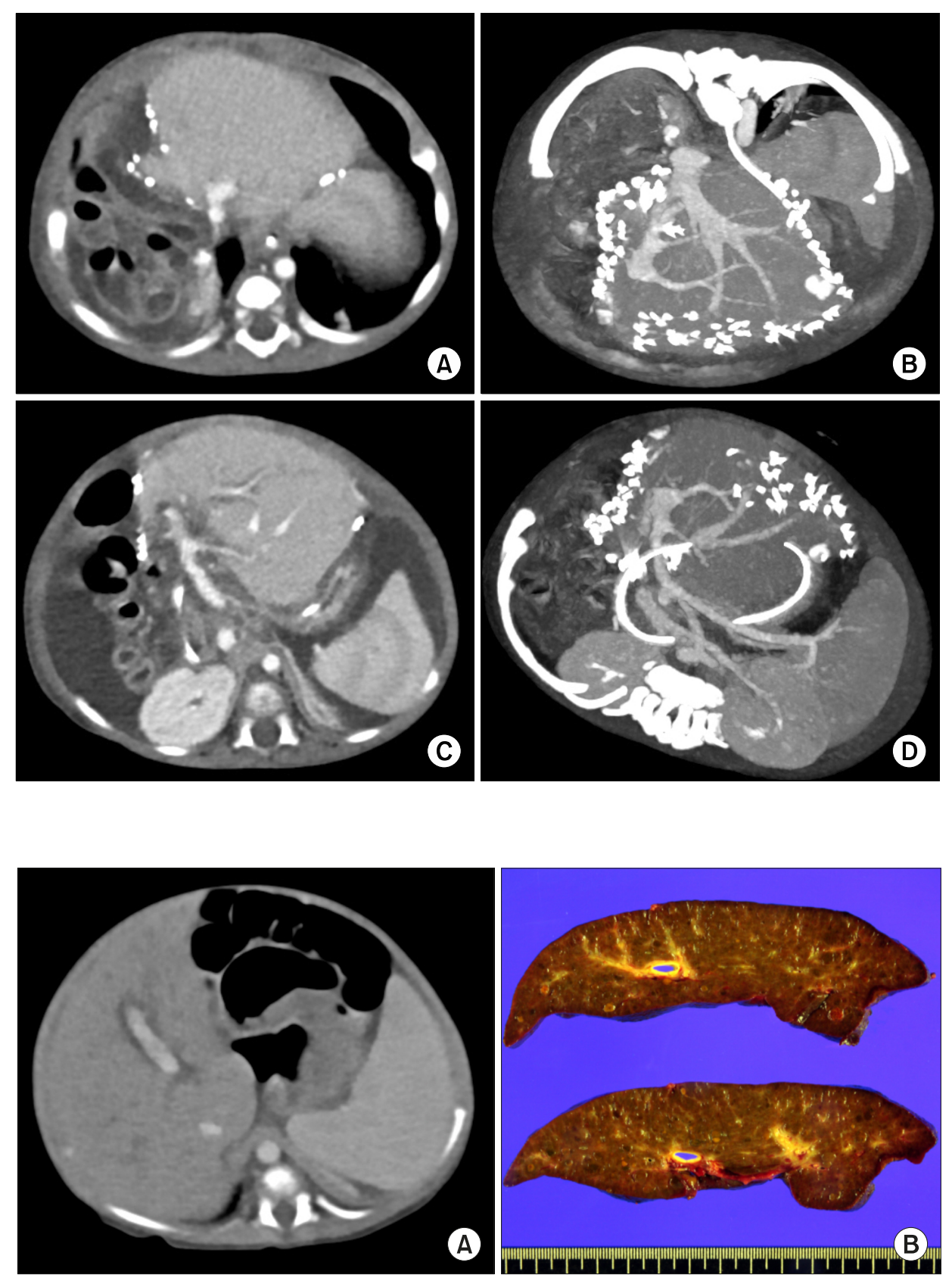

Fig. 8. Computed tomography of the recipient at the age of 2 months (A) and gross photograph of the resected recipient's liver (B) in Case No. 2. 
ter birth, jaundice developed and then hepatomegaly and splenomegaly progressed (Fig. 8). Her general condition and liver function deteriorated progressively, so she was enrolled to the waiting list with the Korean Network for Organ Sharing (KONOS) status 1. The deceased donor was a 20 -year-old female with body weight of $64 \mathrm{~kg}$. After laparotomy, the size of the LLS graft was evaluated by manual palpation. The surface marking was made along the falciform ligament to split a usual LLS graft, and then additional markings were made for size reduction. The liver was split into a right trisegment graft and a LLS graft, and then hepatic resection for size reduction was performed. The weight of the HRLLS graft was $225 \mathrm{~g}$, making a GRWR of $5.49 \%$. The orifice of the graft left hepatic vein appeared similar to a figure of 8 , so unification venoplasty was performed after septotomy and excision of the intervening hepatic parenchyma (Fig. 9).

Recipient hepatectomy was performed according to the standard procedure for pediatric LDLT. Graft implantation was performed according to the standard procedure of LLS implantation. Reconstruction was done in the order of hepatic vein, portal vein, hepatic artery and Roux-en-Y hepaticojejunostomy. The graft was too large to allow primary abdominal wound closure, thus a staged closure was done by means of a temporary coverage with a silo using a prosthetic sheet, a temporary abdominal wall closure with Permacol patch (porcine dermal collagen implant, Medtronic, USA), and a final primary closure at 13 days after transplantation. She recovered slowly (Fig. 10) and was discharged at 68 days after transplantation. Currently, she has been doing well for 6 years after transplantation.

Case No. 3: The patient was a 6-month-old $6.9 \mathrm{~kg}$ weighing female infant with biliary atresia. She was born in full-term delivery through a cesarean section. She underwent Kasai portoenterostomy at 1 month of age. Her general condition and liver function deteriorated progressively, so she was enrolled on the KONOS waiting list for split LT (Fig. 11).

The deceased donor was a 32-year-old $78 \mathrm{~kg}$-weight male. In situ splitting and size reduction was performed according to the abovementioned methods. The HRLLS graft weighed $230 \mathrm{gm}$, thus making a GRWR of $3.33 \%$. Graft implantation was performed according to the stand-
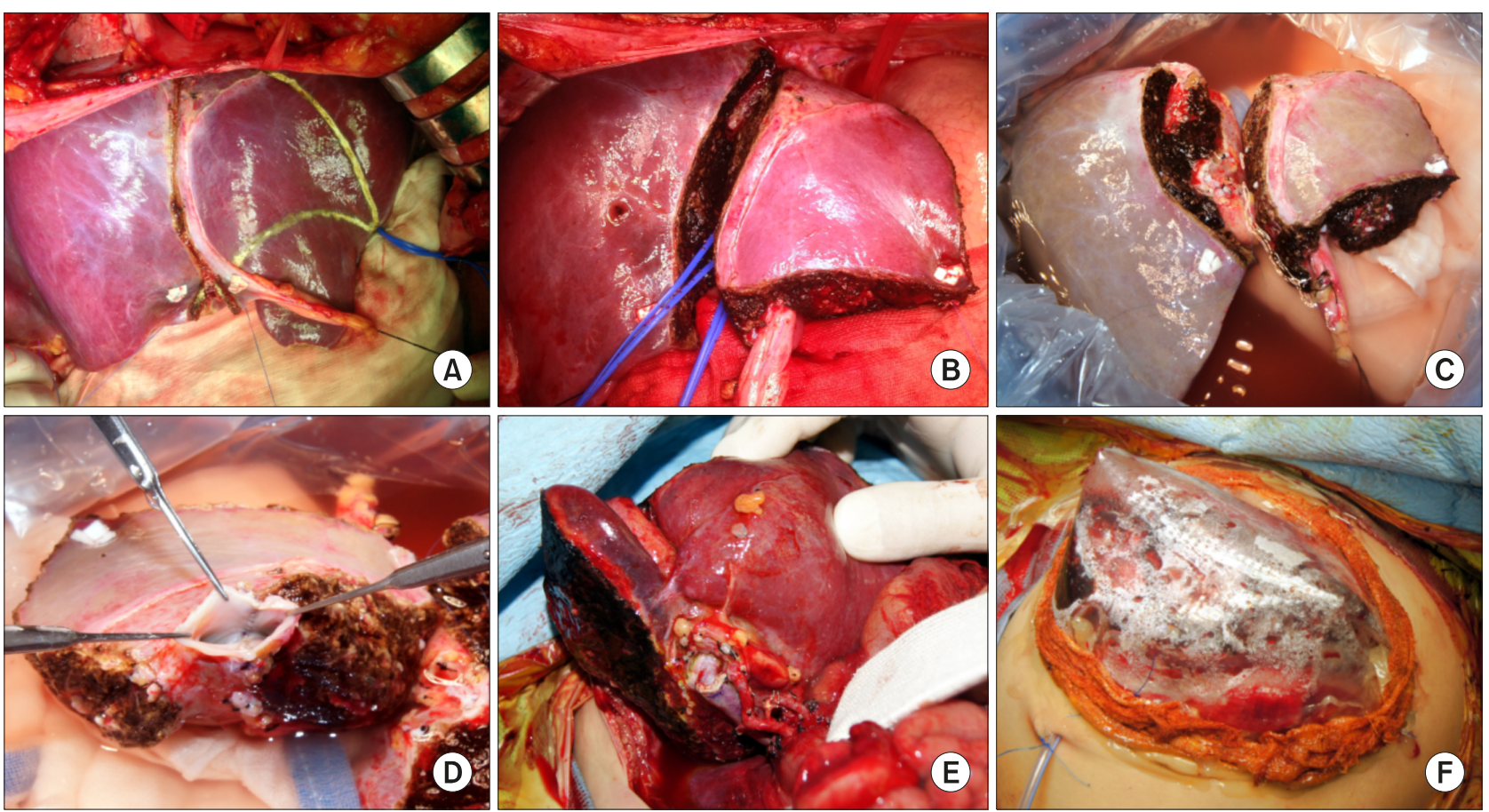

Fig. 9. Intraoperative photographs showing the surgical procedures for making a split hyperreduced left lateral segment graft in Case No. 2. (A) The lines for liver splitting and size reduction were drawn on the liver surface. (B) The liver was split and size was also reduced. (C) The whole split liver was harvested. (D) An unification venoplasty was performed after septotomy and excision of the intervening hepatic parenchyma. (E) The hyperreduced liver graft was implanted. (F) The protruded liver graft was covered by a silo. 

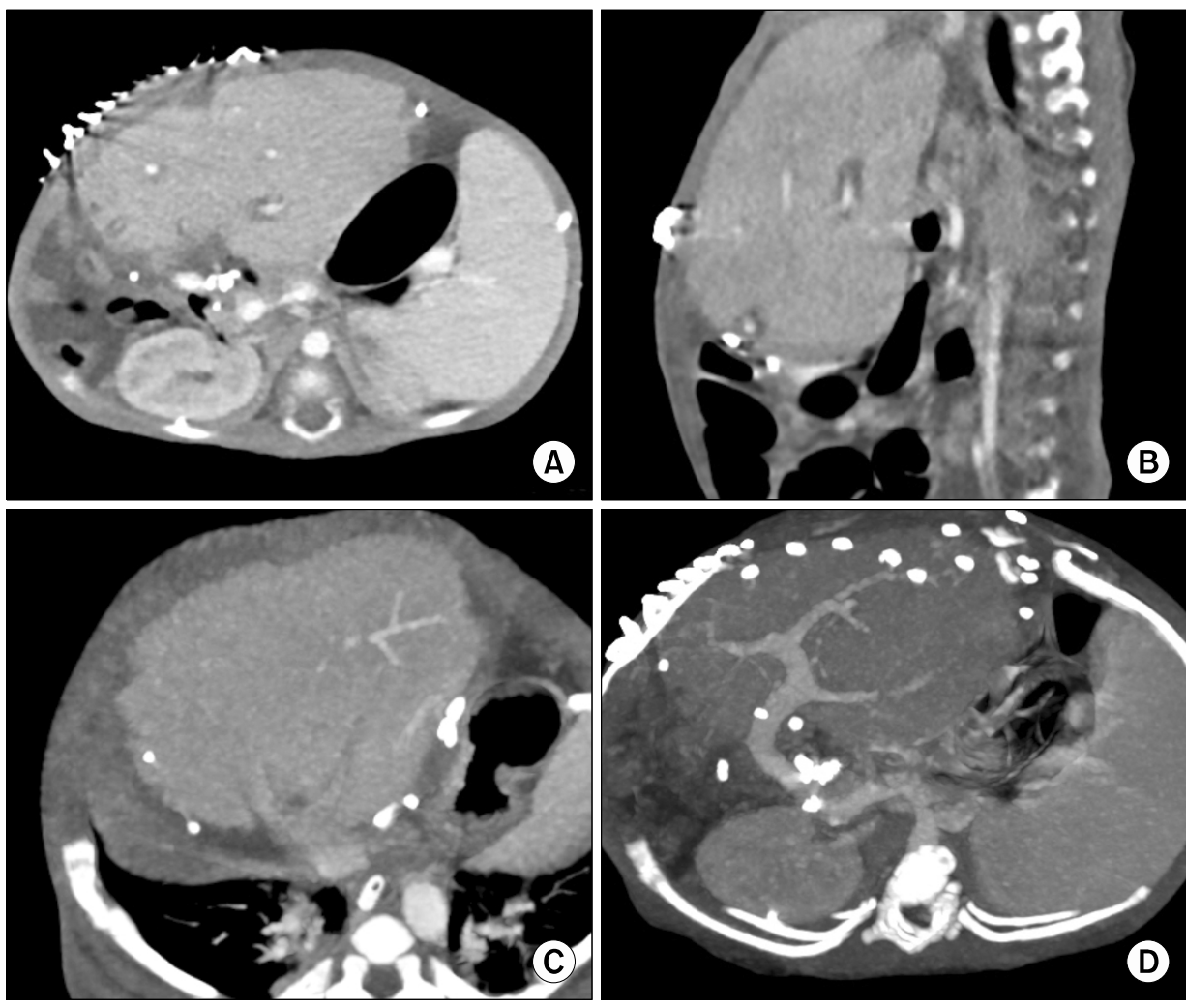

Fig. 10. Computed tomography scan taken 14 days after transplantation in Case No. 2. The abdominal wall was closed completely (A and $\mathrm{B}$ ), and the graft hepatic vein (C) and portal vein (D) reconstructions were uneventful.
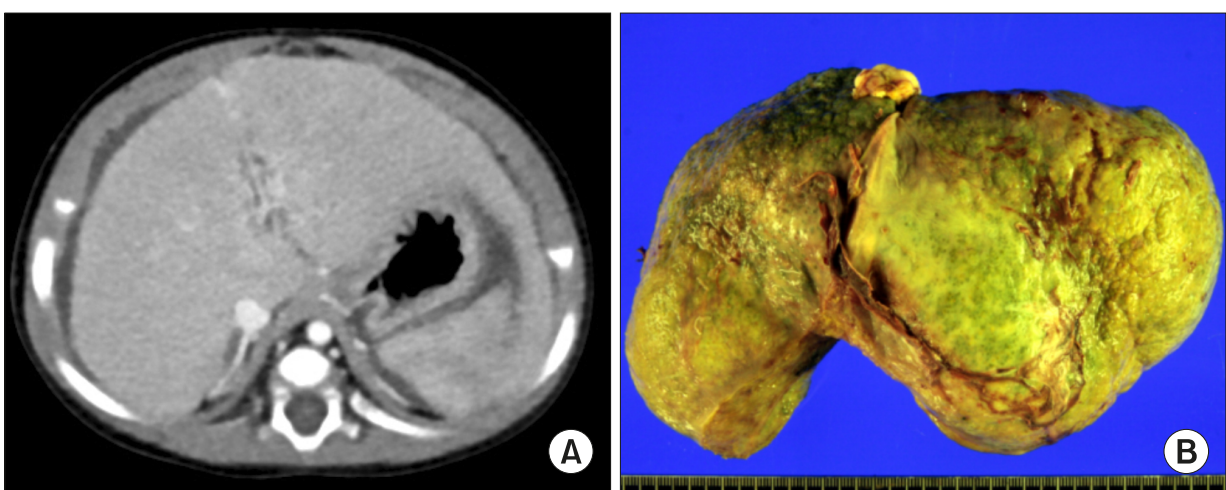

Fig. 11. Computed tomography of the recipient at the age of 5 months (A) and gross photograph of the resected recipient's liver (B) in Case No. 3.

ard procedures of LLS implantation. Since there was portal vein hypoplasia, the donor's external iliac vein segment was used for interposition graft. Graft reconstruction was done in the order of hepatic vein, portal vein, hepatic artery and Roux-en-Y hepaticojejunostomy. The abdominal wound was temporarily closed with a Permacol patch because the graft was too large to be accommodated within the abdomen (Fig. 12). At 7 days, the abdomen wound was primarily closed. The posttransplant recovery was uneventful (Fig. 13) and this patient was discharged at 40 days after transplantation. Currently, she has been doing well for more than 7 years after transplantation.

\section{DISCUSSION}

Experience with LT for small infant patients has been accumulating worldwide, but it is still regarded as challenging because large-for-size graft-related problems are big huddles for successful LT. The main problems of large-for-size grafts include the risk of abdominal compartment syndrome caused by the recipient's small abdominal cavity, size discrepancies in vessel size, and insufficient portal circulation and tissue oxygenation ${ }^{1,12-15}$ To solve these critical problems, it is necessary to reduce the size of LLS grafts as much as possible, by making 

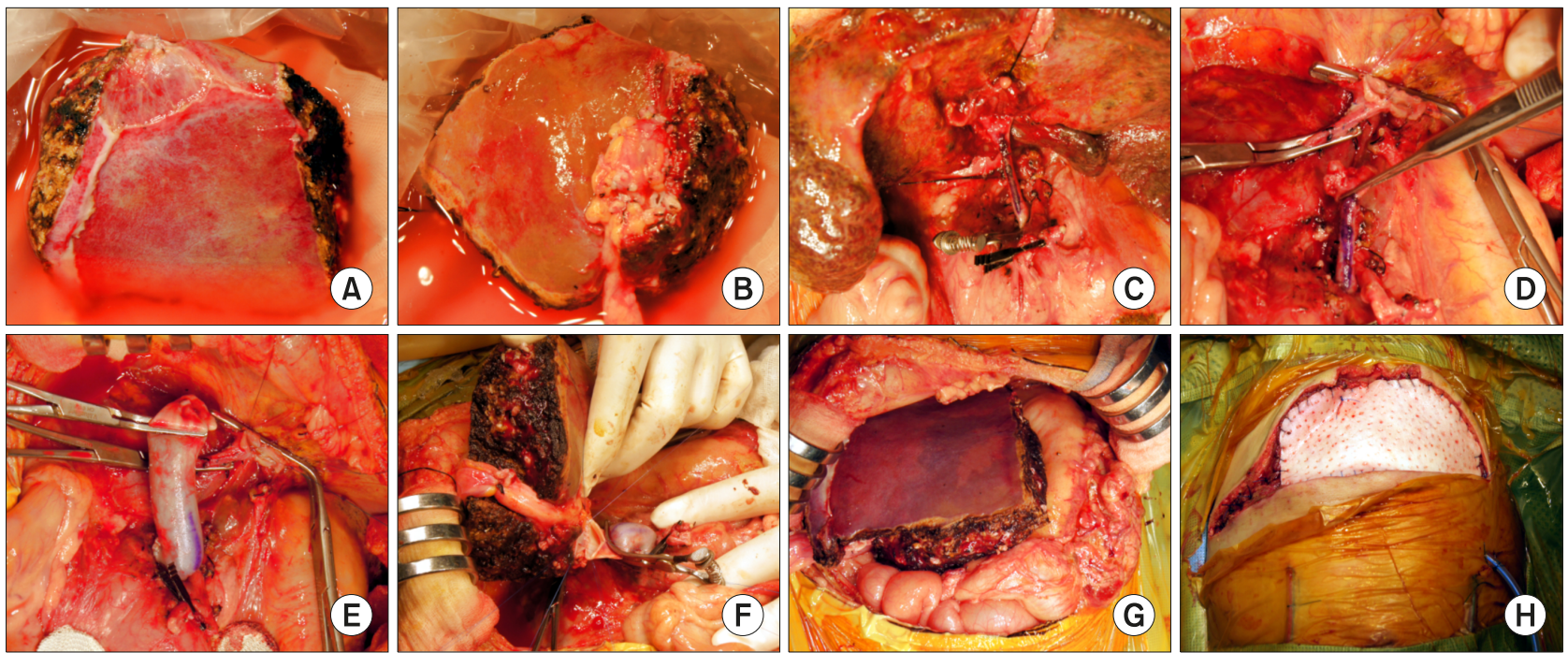

Fig. 12. Intraoperative photographs showing the surgical procedures for implantation of a split hyperreduced left lateral segment graft in Case No. 3. (A and B) The reduced graft was harvested. (C) The recipient's portal vein was hypoplastic. (D) Recipient hepatectomy was performed. (E and F) The recipient's portal vein was replaced with an external iliac vein homograft and portal vein reconstruction was performed. ( $\mathrm{G}$ and $\mathrm{H}$ ) The reduced graft was implanted, but it was too large to be accommodated within the abdomen, so the abdominal wound was temporarily closed with a xenograft patch.
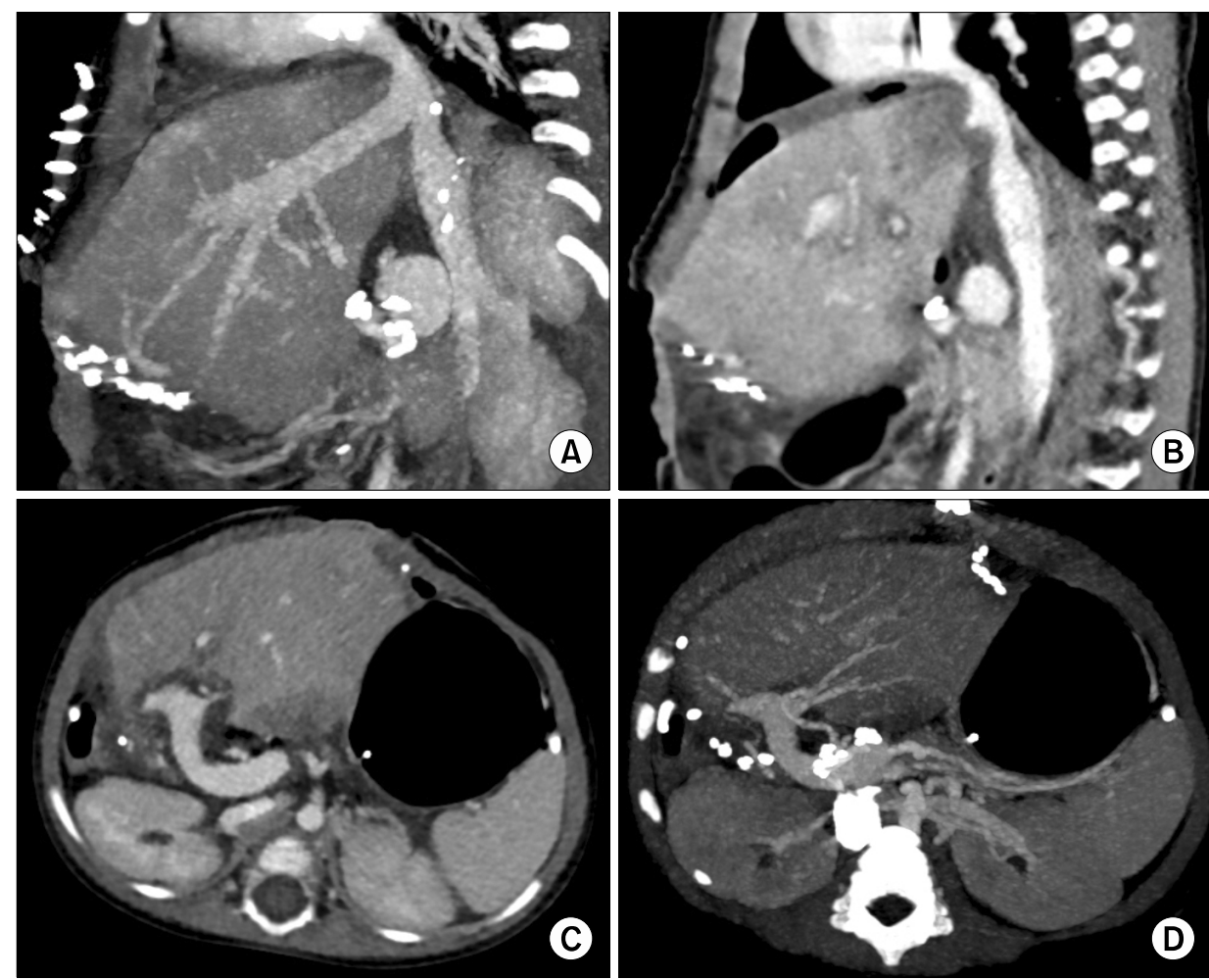

Fig. 13. Computed tomography scan taken at 5 days after transplantation in Case No. 3. The abdominal wall was temporarily closed with a thin patch (A and $\mathrm{B})$, and the graft hepatic vein $(\mathrm{A}$ and $\mathrm{B})$ and portal vein $(\mathrm{C}$ and $\mathrm{D})$ reconstructions were uneventful.

a monosegment or hyperreduced LLS graft.

The target size in graft size reduction is to make the estimated GRWR less than $4 \%$ for LT in infant patients. Anatomically, a monosegment graft would be ideal for making a very small liver graft with effective reduction in graft thickness. However, it is more demanding to make a monosegment graft than a HRLLS graft. It is essential to assess the donor liver anatomy thoroughly to make a monosegment graft, hence it is not usually practical to do that during split LT. In contrast, in situ 
non-anatomical resection used in making a HRLLS graft is technically easier and more intuitive than is an anatomical monosegmentectomy.

The shape of a HRLLS graft is also important because non-anatomical resection is not effective for reducing the graft thickness. ${ }^{1}$ The graft shape was evaluated using the graft thickness-to-anteroposterior diameter in the recipient's abdominal cavity ratio. ${ }^{10}$ If this ratio of thickness exceeds 1.0 , the primary abdominal wall closure can induce graft compression and abdominal compartment syndrome, so temporary closure with a prosthetic mesh should be taken into account. However, it is more difficult to assess the graft thickness during split LT than during LDLT because liver imaging studies are not always available. Both patients who underwent split LT in this series failed to achieve primary abdominal wound closure, because the HRLLS grafts were still too large and too thick to fit within the abdominal cavity directly.

Implantation of a large-for-size graft can induce various vascular complications. The anastomosis site of the graft hepatic vein would be compressed or twisted because of the graft compression by the tight abdominal wall, which can lead to hepatic vein outflow obstruction. To prevent such detrimental effect of extrinsic compression to the graft hepatic vein, customized unification venoplasty making a common channel is helpful to facilitate outflow vein drainage. ${ }^{16,17}$ Since the amount of portal blood flow is small in small infant patients, there is a potential risk of portal hypoperfusion of the graft. Any anastomotic stenosis can interfere with the portal blood supply to the graft, so branch patch of the recipient portal vein was used for recipients with normal portal vein. If there is portal vein hypoplasia, which is often observed in biliary atresia, interposition of vein homograft is effective for preventing anastomotic stenosis and portal hypoperfusion. ${ }^{11}$

The surgical technique for in situ size reduction to make a HRLLS is the same for both living and deceased donors, primarily because it is performed on non-anatomy basis and surgeons' experience-based intuition. A definite demerit in HRLLS is that this technique is not effective for reducing the graft thickness. Thus, prudent selection of a suitable donor is important to compensate for such a technical demerit.

If the liver graft is too large to be accommodated within the abdominal cavity, staged closure methods should be used to prevent abdominal compartment syndrome, as is used in infants with gastoschisis. ${ }^{18}$ If the liver graft bulges out prominently, coverage with a silo is necessary. If the liver graft bulges out only slightly, a temporary closure with a mesh is reasonable. Sequential application of these two procedures was applied to one infant in this series.

The vein homografts used in this series were obtained from the deceased donor directly or from the institutional tissue bank of our institution and the Korea Public Tissue Bank. All human tissues stored at the tissue bank were donated after informed consent of donors' family members. All procedures for vascular tissue procurement and processing were complied with Korean legislation and conformed to the ethical and safety concerns for ther-

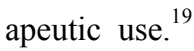

In conclusion, making a HRLLS graft through non-anatomical resection during LDLT and split LT can be a useful option for treating small infant patients.

\section{CONFLICT OF INTEREST}

None of the authors have any conflict of interest.

\section{ORCID}

Jung-Man Namgoong:

https://orcid.org/0000-0002-9237-7440

Shin Hwang: https://orcid.org/0000-0002-9045-2531

Gi-Won Song: https://orcid.org/0000-0002-4235-0434

Dae-Yeon Kim: https://orcid.org/0000-0001-6130-1796

Tae-Yong Ha: https://orcid.org/0000-0001-9932-0212

Dong-Hwan Jung: https://orcid.org/0000-0001-5984-023X

Gil-Chun Park: https://orcid.org/0000-0003-1631-3258

Chul-Soo Ahn: https://orcid.org/0000-0002-3844-3646

Kyung Mo Kim: https://orcid.org/0000-0001-7896-6751

Seak Hee Oh: https://orcid.org/0000-0002-9672-8877

Hyunhee Kwon: https://orcid.org/0000-0001-6647-9155

Yong Jae Kwon: https://orcid.org/0000-0001-9490-1229

\section{AUTHOR CONTRIBUTIONS}

Conceptualization: SH. Data curation: GWS, DYK, TYH, DHJ, GCP, CSA. Methodology: KMK, SHO, HK, YJK. Visualization: SH. Writing - original draft: JMN, SH. 
Writing - review \& editing: SH.

\section{REFERENCES}

1. Kanazawa H, Sakamoto S, Fukuda A, Uchida H, Hamano I, Shigeta $\mathrm{T}$, et al. Living-donor liver transplantation with hyperreduced left lateral segment grafts: a single-center experience. Transplantation 2013;95:750-754.

2. Shehata MR, Yagi S, Okamura Y, Iida T, Hori T, Yoshizawa $A$, et al. Pediatric liver transplantation using reduced and hyper-reduced left lateral segment grafts: a 10-year single-center experience. Am J Transplant 2012;12:3406-3413.

3. Ardiles V, Ciardullo MA, D'Agostino D, Pekolj J, Mattera FJ, Boldrini GH, et al. Transplantation with hyper-reduced liver grafts in children under $10 \mathrm{~kg}$ of weight. Langenbecks Arch Surg 2013;398:79-85.

4. Thomas N, Thomas G, Verran D, Stormon M, O’Loughlin E, Shun A. Liver transplantation in children with hyper-reduced grafts - a single-center experience. Pediatr Transplant 2010;14: 426-430.

5. Yamada N, Sanada Y, Hirata Y, Okada N, Wakiya T, Ihara Y, et al. Selection of living donor liver grafts for patients weighing $6 \mathrm{~kg}$ or less. Liver Transpl 2015;21:233-238.

6. Sakuma Y, Sasanuma H, Miki A, Shimizu A, Sata N, Yasuda $\mathrm{Y}$, et al. Living-donor liver transplantation using segment 2 monosegment graft: a single-center experience. Transplant Proc 2016;48:1110-1114.

7. Hong SK, Suh KS, Kim HS, Yoon KC, Ahn SW, Kim H, et al. Pediatric living donor liver transplantation using a monosegment procured by Pure 3D laparoscopic left lateral sectionectomy and in situ reduction. J Gastrointest Surg 2018;22:11351136.

8. Srinivasan P, Vilca-Melendez H, Muiesan P, Prachalias A, Heaton ND, Rela M. Liver transplantation with monosegments. Surgery 1999;126:10-12.

9. Lee S, Lee SK. Pediatric liver transplantation. J Korean Assoc Pediatr Surg 2013;19:14-21.
10. Sakamoto S, Kanazawa H, Shigeta T, Uchida H, Sasaki K, Hamano I, et al. Technical considerations of living donor hepatectomy of segment 2 grafts for infants. Surgery 2014;156: 1232-1237.

11. Hwang S, Kim DY, Ahn CS, Moon DB, Kim KM, Park GC, et al. Computational simulation-based vessel interposition reconstruction technique for portal vein hypoplasia in pediatric liver transplantation. Transplant Proc 2013;45:255-258.

12. Kiuchi $\mathrm{T}$, Kasahara $\mathrm{M}$, Uryuhara $\mathrm{K}$, Inomata $\mathrm{Y}$, Uemoto $\mathrm{S}$, Asonuma $\mathrm{K}$, et al. Impact of graft size mismatching on graft prognosis in liver transplantation from living donors. Transplantation 1999;67:321-327.

13. Kasahara M, Fukuda A, Yokoyama S, Sato S, Tanaka H, Kuroda $\mathrm{T}$, et al. Living donor liver transplantation with hyperreduced left lateral segments. J Pediatr Surg 2008;43:1575-1578.

14. Vanatta JM, Esquivel CO. Status of liver transplantation in infants $<5$ kg. Pediatr Transplant 2007;11:5-9.

15. Raices M, Czerwonko ME, Ardiles V, Boldrini G, D'Agostino D, Marcó Del Pont J, et al. Short- and long-term outcomes after live-donor transplantation with hyper-reduced liver grafts in low-weight pediatric recipients. J Gastrointest Surg 2019;23: 2411-2420.

16. Hwang S, Kim KH, Kim DY, Kim KM, Ahn CS, Moon DB, et al. Anomalous hepatic vein anatomy of left lateral section grafts and customized unification venoplasty for pediatric living donor liver transplantation. Liver Transpl 2013;19:184-190.

17. Namgoong JM, Hwang S, Park GC, Kwon H, Kwon YJ, Kim SH. Graft outflow vein unification venoplasty with superficial left hepatic vein branch in pediatric living donor liver transplantation using a left lateral section graft. Ann Hepatobiliary Pancreat Surg 2020;24:326-332.

18. Kidd JN Jr, Jackson RJ, Smith SD, Wagner CW. Evolution of staged versus primary closure of gastroschisis. Ann Surg 2003; 237:759-764; discussion 764-765.

19. Kwon H, Kwon H, Hong JP, Han Y, Park H, Song GW, et al. Use of cryopreserved cadaveric arterial allograft as a vascular conduit for peripheral arterial graft infection. Ann Surg Treat Res 2015;89:51-54. 